\title{
What are the reasons why bad science is being naturally selected?
}

\section{Leonardo Bianco de Carvalho}

This brief note is based on an article recently published by Paul E. Smaldino and Richard McElreath (in Source) in the Royal Society Open Science journal. In this publication, Smaldino and McElreath indicate that poor research design and evidence data analysis are frequent issues found in current publications, encouraging false-positive findings. The authors think the reason why poor methods persist are (i) from incentives that favour them or/and (ii) from something more than just misunderstanding, once perennial calls for improvement are taken. In fact, this is leading to the natural selection of bad science, according to the authors.

In another critical point, Smaldino and McElreath also show evidence that once publication is a principal factor for career advancement; some normative methods of analysis have almost certainly been selected to further publication instead of discovery. The understanding of this "dynamic system" requires no conscious strategizing by scientists, according to the authors. In fact, in an environment in which one must publish, independent on the quality or the significance, to advance in the career and not perish, one does not care about false-positive findings (we can find exceptions, of course).

They prove/provide evidence their point of view with empirical basis (you can check in the Source) and conclude that the improvement of the quality of research requires change at the institutional level. The authors are finally emphatic in pointing out that to improve the culture of science, a great/significant shift must be made away from correcting misunderstandings and towards rewarding understanding. So, (almost) all of us can fail in finding the best way for science.

\section{SOURCE}

Smaldino PE and McElreath R. 2016. The natural selection of bad science. Royal Society Open Science 3: 1-17.

Universidade Estadual Paulista, Jaboticabal, SP, Brasil.

*Author for correspondence <lbcarvalho@fcav.unesp.br> 